[ DANIELA SCHMITZ ]

Publicitária. Mestre em Comunicação pela Unisinos, doutora em Comunicação e Informação pela Universidade Federal do Rio Grande do Sul onde, atualmente, é pós-doutoranda em Comunicação e bolsista Capes.

E-mail: danischmitz@ymail.com

\title{
0 processo de midiatização e o sonho de ser modelo
}

\author{
The process of mediatization and \\ the dream of becoming a model
}

\begin{abstract}
[resumo] Tendo como base minha tese de doutorado Vivendo um projeto em família: consumo midiático, beleza feminina e o sonho juvenil de ser modelo profissional, que investigou a participação da mídia - e, igualmente, da família - na construção do desejo de ser modelo profissional, este artigo propõe uma discussão centrada na análise dos dados quantitativos sobre o consumo midiático das informantes, obtidos por meio de questionários aplicados on-line e presencialmente com 79 garotas entre 12 e 25 anos, que sonham em seguir essa profissão. 0 processo de midiatização é o contexto a partir do qual se busca compreender o empírico.
\end{abstract}

\section{palavras-chave}

\section{consumo midiático; midiatização; modelo.}

[abstract] Based on my doctoral thesis Living a project in family: media consumption, female beauty and the youthful dream of becoming a professional model, that investigates the participation of the media (and also family) in the construction of the desire to be a professional model. The discussion is centered on the analysis of quantitative data on the media consumption of the informants, built from questionnaires applied on-line and in person with 79 girls between 12 and 25 who dream of having this profession. The process of mediatization is the context from which we seek to understand the empirical.

[keywords] media consumption; mediatization; model. 
0 processo de midiatização e o sonho de ser modelo

A midiatização' é vista aqui como um fenômeno corrente e não um conceito fechado a partir do qual seja possivel ler uma realidade empírica. Dessa forma, opta-se em trazer algumas discussões de autores que guiam o olhar lançado aos dados construídos em campo.

Para trabalhar o fenômeno da midiatização, parte-se do pressuposto de que é cada vez maior a participação e importância do campo midiático na configuração das sociedades contemporâneas. Na contemporaneidade, os sujeitos acostumaram-se com o fato de que é principalmente por meio da mídia que são informados sobre os acontecimentos e o curso do mundo. Ela transmite dados atualizados que favorecem a adaptação ao meio cambiante, o que acaba por mudar, em alguma medida, a forma de experienciá-lo. Nessa reconfiguração social, o campo midiático possui "(...) a característica de atravessar todos os outros campos, condicioná-los e adequá-los às formas expressivas e representativas da mídia" (TORRE, 2002, p. 4). Esse processo tomou fôlego na segunda metade do século $X X$, outorgando à mídia um papel estratégico em nossa sociedade, com cada vez maior autonomização do campo da mídia (RODRIGUES, 2000).

Assim, fica-se atento para o poder de reorganização social que o campo midiático adquire na atualidade, tomando uma posição para além de seu papel mediador/representador, tal qual ocorria na sociedade massiva. Nesse período, a cultura massiva era entendida estritamente como um conjunto de objetos produzidos para as massas e consumidos por elas, numa concepção que desconsiderava o papel configurador da mídia tanto do comportamento individual como do social, bem como da produção de sentidos. A ação concreta da midiatização teve como consequência uma remodelagem do tecido social, com uma nova conformação das interações que, segundo Mata (1999, p. 82, tradução nossa), nos coloca diante de:

uma nova matriz para a produção simbólica dotada de um estatuto próprio e complexo que congrega antigos modos de interação com novas formas de expressão, antigos circuitos de produção com novas estratégias discursivas e de recepção. ${ }^{2}$

Ao argumentar acerca do processo de midiatização a partir da centralidade da mídia nas trocas sociais, Verón (1997) preocupa-se com a problemática da influência dos meios de comunicação sobre os mecanismos de funcionamento social e com as novas sociabilidades que surgem a partir das novas tecnologias de comunicação. 0 autor aponta para uma conceituação de comunicação midiática na qual se articulam os dispositivos tecnológicos, as condições específicas de produção e as práticas de recepção, numa imbricação entre a mídia, as instituições e os atores individuais.

Desse modo, tem-se hoje um panorama social no qual as experiências são cada vez mais permeadas por relações comunicacionais que, em determinado momento, são perpassadas pela mídia, promovendo novas formas de interação social: as esferas da vida social e individual muitas vezes se reorganizam em função da lógica midiática.

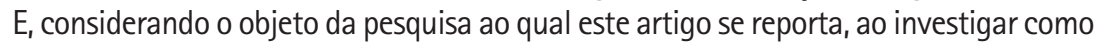
as familias vivem e constroem o sonho de adentrar no universo da mídia a partir do desejo da filha de ser modelo, entende-se que será possivel compreender como a lógica midiática perpassa a estrutura e as relações familiares, sem, no entanto, substituir ou suplantar laços outros que formam vínculos.

Entende-se que as perspectivas de Mata (1999) e Verón (1997) ajudam a pensar o processo de construção do desejo das jovens (e de suas famílias) de figurar/pertencer à esfera midiática, tendo como pressuposto que esse desejo se configura, em grande medida, a partir do consumo da mídia, mais especificamente dos modelos midiáticos de aparência feminina. Compreende-se também que, na busca pelo sonho de ser modelo, muitas garotas se apropriam do discurso e de lógicas da mídia para dela conseguir fazer parte, construindo um projeto de vida ${ }^{3}$ que contempla o consumo da beleza feminina midiatizada e colocando em prática essa forma de ação da mídia para pertencer a esse universo dos meios de comunicação. 
No contexto em que se focaliza o fenômeno da midiatização, entende-se que ele ocorre em vários níveis da vida social e nas necessidades cada vez maiores de entendimento e apropriação das lógicas midiáticas de atuação para experienciar o mundo. Ainda que não trabalhe com um conceito de midiatização, Lipovetsky (1989) aborda a questão com vistas em sua incidência sobre os sujeitos e vê na lógica da mídia um reforço para o individualismo contemporâneo:

[...] a mídia não asfixia o sentido da comunicação, não põe fim à sociabilidade, mas reproduz de uma outra maneira ocorrências de troca social. Instituem-na essencialmente sob uma forma menos ritualizada e mais livre. [...] [os indivíduos] comunicam-se de maneira mais estiIhaçada, mais informal, mais descontínua, de acordo com os gostos de autonomia e de rapidez dos sujeitos. (LIPOVETSKY, 1989, p. 235)

Lipovetsky (1989) também vê uma aproximação grande entre moda e mídia em suas lógicas de funcionamento. Lembrando que, para o autor, a dinâmica da moda é uma "forma" geral em ação no todo social. Para ele, a sociedade de consumo está estruturalmente imersa na lógica da moda, pois reordena a produção e o consumo de massa sob três princípios básicos da forma moda: obsolescência, sedução e diversificação. 0 atual funcionamento das indústrias de consumo estaria repetindo um "modelo" criado pela alta-costura em que as bases de funcionamento estão fixadas na "lógica da renovação precipitada, da diversificação e da estilização de modelos" (LIPOVETSKY, 1989, p. 159). Sobre as relações entre moda e mídia - importantes para a pesquisa, pois a profissão de modelo está intimamente ligada à moda e é a partir da midiatização das imagens das modelos que a profissão se efetiva -, Lipovetsky enumera que o "tempo-moda" (acelerado) também existe na mídia, que ambas (moda e mídia) estão interessadas no sucesso e lucro imediatos, dedicam grande importância à imagem, ambas trabalham com a construção de celebridades, disponibilizam uma diversidade de ofertas para todos os gostos, e a existência de ambas é sem prolongamentos, ou seja, construída para o presente. Na argumentação do autor é possível perceber uma série de estratégias que fazem parte da lógica midiática de atuação, contrariando estudos que desconsideram essa aproximação entre moda e mídia.

No caso da referida pesquisa, que envolve o consumo da aparência feminina midiatizada e o desejo de pertencer à esfera midiática por meio justamente da aparência, seria possivel pressupor que um forte processo de midiatização estaria incidindo. Isso porque as jovens (e também suas familias) precisam conhecer, apropriar-se e adentrar as lógicas midiáticas da beleza que incluem tanto juventude, magreza, altura diferenciada e, de preferência, um padrão europeu de aparência e também uma renovação constante do seu próprio parecer para trilhar com sucesso o suposto caminho da fama. Entende-se que a participação da família no processo de busca por essa carreira também seja marcada pelo fenômeno da midiatização, uma vez que os padrões de aparência feminina são amplamente difundidos e, em certa medida, construídos via mídia, e a lógica midiática faça parte, de alguma forma, do cotidiano familiar.

\section{O consumo midiático e o sonho de ser modelo}

A noção de consumo midiático é uma apropriação do conceito de consumo cultural de Canclini (2006), pois entende-se que os "bens" ofertados pela indústria midiática são de ordem cultural.

Os produtos denominados culturais têm valor de uso e troca, contribuem para a reprodução da sociedade e, às vezes, para a expansão de capital, porém neles os valores simbólicos prevalecem sobre os utilitários e mercantis. (CANCLINI, 2006, p. 88, tradução nossa) ${ }^{4}$

Referindo-se especificamente aos produtos midiáticos, o autor vê nestes algumas especificidades que os distinguem de bens ou atividades culturais, como a arte e as ciências. Canclini (2006) argumenta que muito embora as exigências econômicas interfiram na produção, estilo e circulação dos produtos da mídia, eles possuem uma 
determinada autonomia no que diz respeito à dinâmica própria de seus processos produtivos e seu consumo, o que torna possivel tomá-los como bens culturais.

Assim, com foco nesse tipo de consumo particular, a discussão a seguir parte do mapeamento do consumo midiático de 79 jovens entre 12 e 25 anos que sonham em ser modelo profissional. Esse levantamento foi realizado a partir de um questionário aplicado pela internet, respondido por 46 jovens espalhadas por oito estados brasileiros, e foi aplicado presencialmente com mais 33 garotas de Porto Alegre e região metropolitana que participaram de uma seleção para modelos realizada na capital gaúcha em abril de 2013.

0 consumo midiático foi mapeado de três formas: a) em respostas espontâneas sobre o consumo de informações do universo das modelos, sem que a pergunta remetesse a espaços midiáticos; b) de forma induzida com foco no consumo de mídia no geral. Nesse item questionou-se sobre a frequência de consumo e as preferências nas TVs aberta e por assinatura, internet, rádio, revistas, jornais e cinema para ver se havia alguma predileção por produtos que remetessem ao universo das modelos; e c) de forma induzida com foco no consumo de conteúdos midiáticos sobre modelos. Nesse terceiro momento questionou-se o que já haviam consumido sobre modelos nas TVs aberta e por assinatura, internet, rádio, revistas, jornais e cinema.

Na sequência, apresentam-se alguns dados sobre o consumo midiático e o sonho de ser modelo que possibilitaram antever algumas indicações acerca da participação da mídia na construção do desejo de seguir essa carreira. Aqui, optou-se por não apresentar os gráficos completos, colocando em pauta apenas os principais resultados obtidos em cada eixo de observação.

$\mathrm{Na}$ instauração do desejo, a mídia já é a mais citada pelas jovens, pois, ao serem questionadas sobre o motivo que as levou a pensar em ser modelo, as respostas apontam quatro razões principais: o consumo midiático (33\%), o contato com a profissão/profissionais da área (22\%), as relações sociais (22\%) e a família (16\%).

As modelos mais admiradas são aquelas de maior projeção na mídia: Gisele Bündchen foi indicada por 71\% das entrevistadas, seguida por Ana Hickmann (29\%), Naomi Campbell (19\%) e Isabeli Fontana (9\%). Além dessas profissionais, Heidi Klum, Fernanda Lima, Luiza Brunet, Grazi Massafera e Kate Moss alcançaram 5\% cada uma ${ }^{5}$. Gisele muito provavelmente seja o caso de maior sucesso no mundo das modelos, com espaço cativo na mídia nacional e internacional e com exposição midiática de enquadramento quase sempre positivo. Ana Hickmann, após nove anos trabalhando exclusivamente como modelo, partiu para uma carreira promissora diante das câmeras de televisão. Naomi Campbell alcançou o terceiro lugar nas citações e é a modelo negra mais famosa, tanto que, em seu tratado sobre a beleza, Eco (2007) a colocou entre as principais referências do fim do século passado. Especula-se que essa preferência possa estar relacionada ao fato de que algumas das entrevistadas eram negras e também pela presença midiática de Naomi para além das passarelas, mesmo que em meio a escândalos. Isabeli Fontana, além de top model internacional, coleciona ex-namorados famosos, como o ator Henri Castelli, o cantor Falcão do grupo 0 Rappa e Rohan Marley, filho do cantor Bob Marley. Toda essa exposição midiática em razão dos romances - o que a leva também para as "revistas de fofocas" - pode ter relação com a preferência das entrevistadas, além do fato de ter sua imagem associada a vários produtos de beleza em campanhas publicitárias.

As modelos menos citadas também expandiram seus horizontes profissionais e midiáticos: Heidi Klum e Fernanda Lima iniciaram a carreira como modelo e hoje são apresentadoras de TV; Grazi Massafera já foi miss, modelo, ex-participante de reality show e hoje é atriz global; já Luiza Brunet, atualmente com mais de 50 anos, é uma modelo de grande sucesso no Brasil, tendo atuado como atriz e participado de vários programas de TV. Por fim, Kate Moss talvez seja a única a não se dedicar a nenhuma outra atividade sistemática, mas já flertou com o mundo do rock e do cinema por causa dos namorados famosos, já assinou em conjunto com grandes lojas de departamentos algumas coleções de roupas e é bastante reconhecida por seu estilo de vestir. 
Esse quadro geral das modelos mais admiradas leva a inferir que a exposição na mídia para além da carreira de modelo pode ser determinante para a projeção que elas alcançam no grupo pesquisado, seja em relação ao alcance do meio em que estão expostas (TV aberta ou por assinatura, por exemplo), seja ao tempo de exposição (Naomi e Luiza podem ser consideradas veteranas).

A participação da mídia na construção do desejo de ser modelo também ficou evidente ao se questionar onde as garotas buscam informações sobre a carreira de modelo - a mídia reina como a principal fonte $(97 \%)^{6}$. Importante destacar que essa foi a segunda pergunta do questionário ${ }^{7}$ e também teve resposta totalmente espontânea, ou seja, o assunto "mídia" ainda não estava em pauta, diferentemente das perguntas que vieram a seguir relacionadas especificamente ao consumo de meios.

Entre as garotas que indicaram a mídia como principal fonte de informação sobre a atividade de modelo, 92\% têm a internet como veículo para o consumo midiático de conteúdos sobre o universo das modelos; a televisão, aberta ou por assinatura, surge em segundo lugar (31\%) e as revistas ${ }^{8}$ vêm em seguida (23\%) $)^{9}$. No ambiente on-line, quando houve especificação do espaço em que se dá o consumo, as respostas apontaram para os sites de busca, sites sobre moda, revistas eletrônicas, blogs e redes sociais. Quanto ao consumo na TV (aberta e paga), pouco mais da metade (53\%) não especificou o programa, as que o fizeram indicaram os reality shows sobre a vida de modelos como prediletos (42\%). Infere-se que esses programas façam sucesso por, supostamente, apresentarem a "realidade" do mercado de modelos e ainda possuírem um caráter pedagógico, com aulas e dicas sobre como posar para fotos, desfilar ou como se vestir para concorrer a um trabalho. Contudo, acompanhando esses programas, é possível perceber que, entre uma e outra dificuldade da carreira que é abordada, a glamourização das sessões de fotos, produções de moda e beleza prevalecem. 0 jornal Folha de S.Paulo comenta a respeito da estreia de Meu Agente, programa do Canal E! Entertainment Brasil, citado por algumas garotas: "Apesar dos bons relatos sobre as exigências do mercado, à primeira vista, a impressão que fica é de que por mais difícil que seja o início da carreira de modelo, sempre há um mundo lindo e benevolente à espreita" (DINIZ, 2012). Ainda no consumo de TV, as demais citações giram em torno de desfiles, programas de entrevistas que conversam com modelos e concursos, como o Miss Brasil e o Miss Universo.

Explorando o consumo de meios no geral e o consumo de conteúdos específicos sobre modelos, as entrevistas apontaram que na TV aberta o consumo cotidiano de programas que poderiam ser associados ao universo das modelos não foi muito expressivo. Os programas sobre moda receberam apenas $8 \%$ das indicações e os de celebridades 4\% e são os únicos em que se percebe uma relação mais direta com a profissão e o glamour que ela evoca. Contudo, 67\% das entrevistadas indicaram que já haviam consumido algo sobre modelos nesse meio.

Há de se considerar que a televisão aberta não possui tantos programas que podem ser associados ao universo das modelos. 0 mesmo não ocorre em relação à TV por assinatura, na qual a diversidade e quantidade de ofertas alçou os programas de moda ao segundo lugar com $46 \% 0^{10}$ e os de beleza alcançaram $21 \%$, ficando em quinto lugar no quesito consumo cotidiano.

É no consumo de TV por assinatura que começa a se delinear uma participação mais expressiva da mídia no sonho de ser modelo, isso porque seis programas que estão entre os cinco mais citados podem ser relacionados com a carreira e com o glamour que ela evoca. Ao total, 73 programas da televisão paga foram citados; destes, 17 têm, de alguma forma, relação com a profissão de modelo.

No consumo de internet também é possivel visualizar essa busca de referências da profissão, já que de 34 sites citados, 25 têm relação com os assuntos desse universo (moda, beleza, revistas, agências de modelo), o que equivale a 74\%. Além disso, com base nos dados construídos em campo, pode-se inferir que a internet é o meio mais utilizado para o consumo de temáticas sobre esse universo. Toma-se por base, além da quantidade de sites indicados sobre os assuntos de referência, o fato de a internet ter surgido espontaneamente como principal meio para esse consumo, com 92\% das indicações, como já foi mencionado.

Sobre o meio revista (impresso e on-line), as publicações de moda despontam na preferência com 49\% das indicações, seguem então as revistas adolescentes (30,2\%), 
as femininas $(26,4 \%)$, de informação $(22,6 \%)$ e celebridades (15\%). Ou seja, também aqui delineia-se uma preferência por conteúdos bastante ligados ao universo das modelos, como a moda, que está em primeiro lugar, mas também permeia de forma intensa os assuntos de todos os gêneros que estão nas cinco primeiras colocações, com exceção das revistas de informação. No geral das entrevistadas, 58\% indicaram já ter consumido algo sobre modelos nas revistas.

0 rádio, os jornais e o cinema não foram expressivos no consumo de conteúdos sobre a profissão, embora algumas garotas os tenham citado.

\section{Considerações acerca da pesquisa}

Com base nos dados apresentados, é possível vislumbrar uma relação entre o consumo midiático e o desejo de ser modelo, visto que a participação da mídia já se inicia no despertar do sonho de trilhar essa profissão e segue na oferta de referenciais de modelos consagradas para serem admiradas e, quiçá, copiadas. Lembrando que, quanto maior a participação midiática dessas modelos, além das atividades da profissão, como desfilar e fotografar, maior é o número de vezes que elas são citadas como referência. Assim, podemos depreender que o maior sonho dessas garotas é alcançar sucesso no âmbito midiático, não necessariamente como modelo.

Infere-se também que o consumo atual de mídia esteja mais relacionado com a "manutenção" do desejo de ser modelo, uma vez que 89\% situaram o início do sonho em fase anterior aos 13 anos e a média de idade das entrevistadas é de 17 anos. Tendo em vista a relação atual entre o sonho e o consumo de mídia, a internet, a TV por assinatura e as revistas aparecem como proeminentes, tal resultado pode ser associado ao fato de que esses meios oferecem maior quantidade de conteúdos sobre o universo da profissão.

Mesmo que se tenha optado por discutir dados de natureza quantitativa, é possível inferir que a mídia contribui em grande medida na configuração dos sentidos fabricados sobre a profissão de modelo em razão da quantidade de produtos midiáticos consumidos e também da sua importância na busca por informações sobre a carreira, visto que 97\% usam a mídia como referência. Assim, é possível considerar que o midiático constitui-se de uma matriz para a produção simbólica, como propõe Mata (1999). Resta investigar quais os usos atribuídos a esse consumo e os sentidos a ele associados, aspectos que a tese se propõe a explorar.

Na dimensão empírica, tudo indica que em algumas famílias o sonho da filha de ser modelo é transformado em um projeto de vida, ou seja, ultrapassa essa dimensão onírica e transforma-se em ações concretas na busca pela profissão. E a mídia é usada como referência em várias dessas ações, como a busca por fan pages do Facebook e sites de agências de modelo, informações e inscrições em concursos da área, propagandas de seleções de modelo, cursos etc. Sem contar que o consumo das modelos e do seu universo como um todo é o que mobiliza e alimenta a busca pelo projeto de ser modelo. Nessas organizações familiares em que o desejo da filha pauta o projeto familiar do futuro, as esferas da vida social e individual podem se reorganizar em função da lógica midiática, já que a mídia é o espaço em que as modelos fazem sucesso e onde essas garotas desejam estar.

Por fim, quanto às lógicas midiáticas de atuação, tratadas aqui desde a perspectiva de Lipovetsky (1989) que aproxima moda e mídia, é possível considerar que a construção de celebridades é inerente a esses dois campos e se encontra de forma bastante expressiva na profissão de modelos. Contudo, supõe-se, com base nas observações de inspiração etnográfica que se realizou em eventos de seleção de modelos, que a apropriação das perspectivas de fama, glamour e sucesso inscritas nos conteúdos midiáticos estejam operando, considerando-se o grande número de garotas encontradas nas seleções. No entanto, questiona-se que tipo de apropriação do padrão de aparência das modelos está sendo operado, pois várias jovens ali presentes não se enquadravam no padrão de beleza que o mercado de modelos impõe e que é amplamente disseminado na mídia. 


\section{NOTAS}

${ }^{[1]}$ Aqui o conceito de midiatização parte das noções de consumo midiático - desdobrada do conceito de consumo cultural de Canclini (2006) - e do conceito de mediações de Martín-Barbero (2003).

[2] No original: "[...] una nueva matriz para la producción simbólica dotada de un estatuto propio y complejo en tanto fundía anteriores modos de interacción con nuevas formas expressivas, anteriores circuitos de producción con nuevas estrategias discursivas y de recepción."

${ }^{[3]}$ A noção de projeto de vida é trabalhada a partir de Velho (2003).

${ }^{[4]}$ No original: "Los productos denominados culturales tienen valores de uso y cambio, contribuyen a la reproducción de la sociedade y a veces a la expansión del capital, pero em ellos los valores simbólicos prevalecen sobre los utilitarios y mercantiles."

${ }^{[5]} \mathrm{A}$ soma excede os $100 \%$ pois algumas garotas indicaram mais de uma modelo.

${ }^{[6]}$ As demais fontes indicadas foram: profissionais de agência (6\%), amigas modelos (5\%), cursos (5\%), eventos de moda (3\%). A soma excede os $100 \%$ pois algumas garotas indicaram mais de uma fonte.

${ }^{[7]}$ A primeira pergunta era "Desde quando você quer ser modelo?".

${ }^{[8]}$ Aqui são consideradas as revistas impressas, e o consumo on-line destas foi contabilizado no item internet.

${ }^{[9]}$ Novamente a soma excede os $100 \%$ pois as garotas apontaram mais de uma mídia.

${ }^{[10]}$ Os seriados aparecem em primeiro lugar com $51 \%$. Destaca-se que a soma excede os $100 \%$ pois as garotas indicaram a preferência por mais de um programa.

\section{REFERÊNCIAS}

CANCLINI, N. G. El consumo cultural: uma propuesta teórica. In: SUNKEL, G. El consumo cultural en América Latina: construcción teórica y líneas de investigación. Bogotá: Convenio Andrés Belo, 2006, p. 72-95.

DINIZ, P. Canal E! acompanha o dia a dia de agentes brasileiros de modelos. Folha de S.Paulo. São Paulo, 5 jul. 2012. Disponivel em: <http://www1.folha.uol.com.br/ilustrada/1115026-canal-eacompanha-o-dia-a-dia-de-agentes-brasileiros-de-modelos.shtml>. Acesso em: 11 maio 2013.

ECO, U. História da beleza. Rio de Janeiro: Record, 2007.

LIPOVETSKY, G. 0 império do efêmero: a moda e seu destino nas sociedades modernas. São Paulo: Companhia das Letras, 1989.

MARTÍN-BARBERO, J. Dos meios às mediações: comunicação, cultura e hegemonia. Rio de Janeiro: Editora UFRJ, 2003.

MATA, M. C. De la cultura massiva a la cultura mediática. Diálogos de la comunicación, Lima, n. 56, p. 80-91, 1999. Disponível em: <www.felafacs.org/dialogos>. Acesso em: 20 mar. 2002.

RODRIGUES, A. A gênese do campo dos media. In: SANTANA, R. N. M. (Org.). Reflexões sobre o mundo contemporâneo. Rio de Janeiro: Renan, 2000, p. 201-221.

SCHMITZ, D. M. Vivendo um projeto em família: consumo midiático, beleza feminina e o sonho juvenil de ser modelo profissional. Rio Grande do Sul, 2013. 306 f. Tese (Doutorado em Comunicação e Informação) - Faculdade de Biblioteconomia e Comunicação, Universidade Federal do Rio Grande do Sul.

TORRE, A. E. M. G. Produtos midiáticos, estratégias, recepção: a perspectiva transmetodológica. Ciberlegenda, Rio de Janeiro: UFF, n. 9, p. 1-23, 2002. Disponivel em: <http://www.uff.br/ ciberlegenda/ojs/index.php/revista/article/view/299/0 >. Acesso em: 16 jan. 2014.

VELHO, G. Projeto e metamorfose: antropologia das sociedades complexas. Rio de Janeiro: Zahar, 2003.

VERÓN, E. Esquema para el análisis de la mediatización. Diálogos de la comunicación. Lima, n. 48, p. 9-17, 1997. 